\title{
BMJ Open How primary healthcare in Iceland swiftly changed its strategy in response to the COVID-19 pandemic
}

\author{
Emil Larus Sigurdsson (10 , ${ }^{1,2}$ Anna Bryndis Blondal, ${ }^{2,3}$ Jon Steinar Jonsson, ${ }^{1,2}$ \\ Margret Olafia Tomasdottir, ${ }^{1,2}$ Hannes Hrafnkelsson, ${ }^{1}$ Kristjan Linnet (D) , \\ Johann Agust Sigurdsson ${ }^{4}$
}

To cite: Sigurdsson EL, Blondal AB, Jonsson JS, et al. How primary healthcare in Iceland swiftly changed its strategy in response to the COVID-19 pandemic. BMJ Open 2020;10:e043151. doi:10.1136/ bmjopen-2020-043151

- Prepublication history for this paper is available online. To view these files, please visit the journal online (http://dx.doi org/10.1136/bmjopen-2020043151).

Received 28 July 2020

Revised 21 November 2020 Accepted 23 November 2020

Check for updates

(c) Author(s) (or their employer(s)) 2020. Re-use permitted under CC BY-NC. No commercial re-use. See rights and permissions. Published by BMJ.

${ }^{1}$ Department of Family Medicine, Faculty of Medicine, University of Iceland School of Health Sciences, Reykjavik, Iceland ${ }^{2}$ Development Centre for Primary Healthcare in Iceland, Primary Health Care of the Capital Area, Reykjavik, Iceland ${ }^{3}$ Faculty of Pharmaceutical Sciences, University of Iceland, Reykjavik, Iceland

${ }^{4}$ Faculty of Medicine, Department of Public Health and Nursing/General Practice Research Unit, Norwegian University of Science and Technology (NTNU), Trondheim, Norway

Correspondence to Dr Emil Larus Sigurdsson; emilsig@hi.is

\section{ABSTRACT}

Objective To describe how the primary healthcare (PHC) in Iceland changed its strategy to handle the COVID-19 pandemic.

Design Descriptive observational study.

Setting Reykjavik, the capital of Iceland.

Population The Reykjavik area has a total of 233000 inhabitants.

Main outcome measures The number and the mode of consultations carried out. Drug prescriptions and changes in the 10 most common diagnoses made in PHC. Laboratory tests including COVID-19 tests. Average numbers in March and April 2020 compared with the same months in 2018 and 2019.

Results Pragmatic strategies and new tasks were rapidly applied to the clinical work to meet the foreseen healthcare needs caused by the pandemic. The number of daytime consultations increased by $35 \%$ or from 780 to $1051 / 1000$ inhabitants $(p<0.001)$ during the study period. Telephone and web-based consultations increased by $127 \%(p<0.001)$. The same tendency was observed in out-of-hours services. The number of consultations in maternity and well-child care decreased only by $4 \%$ $(p=0.003)$. Changes were seen in the 10 most common diagnoses. Most noteworthy, apart from a high number of COVID-19 suspected disease, was that immunisation, depression, hypothyroidism and lumbago were not among the top 10 diagnoses during the epidemic period. The number of drug prescriptions increased by $10.3 \%$ (from 494 to 545 per 1000 inhabitants, $p<0.001$ ). The number of prescriptions from telephone and web-based consultations rose by $55.6 \%$. No changes were observed in antibiotics prescriptions.

Conclusions As the first point of contact in the COVID-19 pandemic, the PHC in Iceland managed to change its strategy swiftly while preserving traditional maternity and well-child care, indicating a very solid PHC with substantial flexibility in its organisation.

\section{INTRODUCTION}

The COVID-19 pandemic caused by SARS-COV-2 has challenged the structure, organisation and flexibility of healthcare systems worldwide and has in a certain way led to rebooting of the general practice. ${ }^{1-3}$ In the global health policy, primary healthcare
Strengths and limitations of this study

The data are based on medical records of all contacts to the primary healthcare centres.

- The primary healthcare in the research area serve the whole capital area which counts two-thirds of the population of Iceland.

- The contact register information is very reliable and comprehensive.

- Due to the short study period, that is, 2 months, we were not able to depict the long-term changes in healthcare services.

- The consequences of postponing regular healthcare service are not presented.

(PHC) is the cornerstone of healthcare and the first point of contact. ${ }^{4}$ In epidemics and a pandemic, as the first line of defence, the role of $\mathrm{PHC}$ in the healthcare system is more important than ever. Whereas the hospitals have to concentrate on the disease, peoplecentred PHC has to focus on the patients as well as the health of the whole community at a population health level. In such situations, triage and gatekeeping play a central role. First, the task is to protect the healthcare professionals in the first line of defence from becoming infected. Other important responsibilities include informing the population, identifying and protecting individuals and groups of vulnerable people from getting infected, and last but not least, protecting the tertiary care level, the hospitals so they would not become overwhelmed or out of function because of infected staff and too many COVID-19 cases. Some guidelines have been published to assist general practitioners (GPs) on how to act on COVID-19. ${ }^{56}$

Soon after the information about the spreading of COVID-19 from Wuhan in China in late 2019, Iceland, like other countries, started to prepare for an epidemic (box 1). Before COVID-19 was diagnosed in Iceland 
Box 1 Preparation and implementation of tasks in primary care during COVID-19

Preparation (January 2020)

- Educating staff about COVID-19 disease and the use of personal protective equipment (PPE).

- Providing and ordering appropriate materials and supplies.

- Educating staff about alternative management plans at work.

Testing and treatment

- Patients with symptoms compatible with those of COVID-19 were offered nasopharyngeal and throat testing with specimens collected by doctors and nurses wearing PPE.

- All primary healthcare centres (PHCCs) had daily testing outside their premises, with samples collected while patients were sitting in their cars. At the weekends, the COVID-19 sample collections were centralised at a single place.

- A specially equipped car was used for home visits to those who were too ill to get tested at a drive-through centre.

- COVID-19-positive patients received follow-up care by an outpatient clinic staffed by Landspitali-The National University Hospital of Iceland.

\section{The shift in workload management}

Patient flow systems

- Patients were advised to call in advance before arriving at the PHCCS.

- Telephone consultations were offered instead of appointments.

- The maternity and well-child care consultations were carried out as scheduled.

- Those with symptoms of respiratory tract infections were given appointments at the healthcare centre, which did not overlap with maternity and well-child care consultations.

- New PHCC bookings were scheduled through telephone screening by a nurse or a doctor.

PHC preparedness

- The PHC personnel were divided into two groups: those working at the PHCC and the others at home carrying out phone consultations on the web.

- The PHCCs were separated into two areas, one for patients with respiratory tract infections and the other one for patients without them. Patients with respiratory symptoms were scheduled for the end of the day.

- PHC personnel prioritised work related to COVID-19. Non-urgent appointments were rescheduled, and all group activities cancelled.

- The access of patients was increased through telephone consultations and web chat. For example, school nurses were released from their routine duties so they could conduct telephone COVID-19 consultations.

the Directorate of Health had published a Pandemic National Response Plan. ${ }^{7}$ The plan was updated during the pandemic and adapted to these special circumstances. ${ }^{8}$ After the first case was diagnosed, Iceland's Director of Health, Iceland's Chief Epidemiologist and the National Commissioner of the Icelandic Police's Department of Civil Protection and Emergency Management held daily public meetings with updates on the state of the pandemic and government reactions. Already on 6 March, the team declared the highest alert level, an emergency phase, as a result of the outbreak.
During this pandemic, the PHC in Iceland has had the role as the first point of contact for people with symptoms of the respiratory tract including COVID-19 -like symptoms. Directions or indications for tests were published and promoted by the Directorate of Health. Most of the tests for COVID-19 in clinical situations were taken in primary healthcare centres (PHCCs). Patients with confirmed COVID-19 infection were taken care of by a special unit at Landspitali-The National University Hospital of Iceland. People in quarantine were cared for by the PHC. The organisation of PHC in Iceland was rapidly and substantively changed in order to meet the demands posed by the pandemic.

Thus, when the first case of COVID-19 was diagnosed in Iceland on 28 February 2020, the PHC sector was confronted with an entirely new and unprecedented disease and the PHC preparations and actions taken were accelerated (box 1). To face those challenges, our PHCCs had to adapt swiftly on a much larger scale than ever before, and completely alter their tasks to defeat the enormous and acute encounter ahead. The spread of COVID-19 in Iceland has already been described. ${ }^{9}$ To date, information on the role of PHC in the COVID-19 pandemic is lacking and only a few reports have been published on that matter. ${ }^{10}$

The aim of this paper is to describe the changes in PHC in Iceland during the COVID-19 pandemic, especially in the mode of service and in certain measures of outcomes.

\section{METHODS}

\section{Setting}

The Icelandic healthcare system, like other Nordic welfare systems, is based on solidarity and equitable distribution of services. It is mainly financed through public funds, even though the patient pays some minor fees at the time of service. ${ }^{11}$ The general tasks of the PHCCs are defined by laws and regulations, and their administration is under the auspices of the health authorities. Thus, the management decisions are made locally in accordance with government policy. The healthcare offered by the PHCCs is based on a holistic approach thereby including general practice, maternity care, well-child care, school healthcare, minor surgery and emergency care.

The Capital Region of Iceland had approximately 233 000 inhabitants at the beginning of 2020, or almost twothirds of the total 364000 inhabitants. ${ }^{12}$ The PHC in Reykjavik, the capital area, has 19 PHCCs. The PHCCs are staffed by GPs, midwives, nurses, psychologists and other personnel. The Capital Region has PHC out-of-hours service, and a walk-in clinic which also provides home visits for those too sick to attend the clinic. Additionally, PHC operates a web chat for all residents.

The access to PHCCs is through prebooked face-to-face consultations, phone consultations, web-based consultations and home visits. Furthermore, a walk-in service at the PHCCs is available during daytime for more acute needs. 
It was clear from the beginning of the pandemic that through advertisements in the media and on-site posters in PHCCs, triage was needed. A week later, all patients with a prebooked appointment were offered a phone consultation instead of an inperson visit.

At the beginning of March, patients with symptoms compatible with those of COVID-19 were offered a test. All PHCCs had daily testing outside their healthcare premises, with samples collected through the windows of the patients' cars. Doctors and nurses wearing all the necessary personal protective equipment, collected nasopharyngeal and throat samples from patients. During the weekends, COVID-19 virus testing was centralised in one place. Moreover, during the day and out of hours, a specially equipped car was used for home visits to those too sick to get tested at a drive-through centre. In these visits, samples were collected and people were assessed for the need of hospital admission. COVID-19positive patients received follow-up care by an outpatient clinic operated by Landspitali-The National University Hospital of Iceland.

\section{Data source}

Data were extracted from the medical records database of the PHC in Iceland. The PHC has a common medical records database that is accessible by the PHCCs. The number of contacts to PHC, types of contact, most common diagnoses according to ICD-10 (International Classification of Diseases, Tenth Revision) version of the classification system for diagnoses and medical prescriptions were observed for March and April in the years 2018, 2019 and 2020. The number of blood and urine tests was gathered from the laboratory at Landspitali-The National University Hospital of Iceland. Furthermore, the number of COVID-19 tests performed in March and April 2020 was obtained from the Directorate of Health.

\section{Data analyses}

The data analyses are descriptive and analytical, centring on changes in the services provided during these periods. All $\mathrm{p}$ values are two-sided and the statistical significance was considered at $\mathrm{p}$ values less than 0.05 , using an exact test based on the Poisson distribution for rates. Results are presented per 1000 inhabitants. R statistical software was used for analysis.

\section{Patient and public involvement}

No patient involved.

\section{RESULTS}

Implementation of tasks and shift in workload management are shown in box 1. From the beginning, the PHC prioritised work related to COVID-19, and matters that could wait were set aside. School nurses were called in to do phone consultations related to COVID-19. New PHC appointments were booked through telephone screening by a nurse or a doctor and great emphasis was put on providing maternity and well-child care.

The healthcare centres were also divided into two areas, either for patients with or without symptoms of respiratory tract infection.

As of the middle of March, the PHCCs and the afterhours service designated special rooms in their premises for patients with possible infections and all staff wore masks and gloves for general consultations. From the very beginning it was emphasised that people should call ahead to the PHCC in order to get permission to present there. This message was driven home with increased intensity as the pandemic approached its culmination. Furthermore, when receptionists at the PHCC contacted clients who had appointments in order to offer a telephone consultation, they were asked either to call in advance or refrain from turning up if any common cold symptoms should arise in the meantime.

\section{Consultation rates and modalities}

On average during the two periods, March/April 2018 and 2019, the number of daytime consultations were $780 / 1000$ inhabitants. In the same period in 2020 the consultations were $1051 / 1000$ inhabitants which is a $35 \%$ $(\mathrm{p}<0.001)$ increase from the average number per 2018 and

Table 1 Number and mode of consultation in primary healthcare centres and out-of-hours service during March and April 2018/2019 versus 2020

\begin{tabular}{|c|c|c|c|c|c|c|c|c|c|c|c|c|}
\hline & \multicolumn{4}{|l|}{ PHC } & \multicolumn{4}{|l|}{ OHS } & \multicolumn{4}{|l|}{ Total } \\
\hline & $2018 / 2019$ & 2020 & & & $2018 / 2019$ & 2020 & & & $2018 / 2019$ & 2020 & & \\
\hline & $\mathbf{N}$ & $\mathbf{N}$ & $\%$ & $P$ value & $\mathbf{N}$ & $\mathbf{N}$ & $\%$ & $P$ value & $\mathbf{N}$ & $\mathbf{N}$ & $\%$ & $P$ value \\
\hline Office visits & 357 & 209 & -41 & * & 69 & 37 & -46 & * & 426 & 246 & -42 & * \\
\hline Home visits & & & & & 4 & 7 & +75 & * & 4 & 7 & +75 & * \\
\hline
\end{tabular}

$\mathrm{N}=$ number per 1000 inhabitants.

${ }^{*}$ All changes are statistically significant, $p<0.001$.

OHS, out-of-hours service; PHC, primary healthcare. 


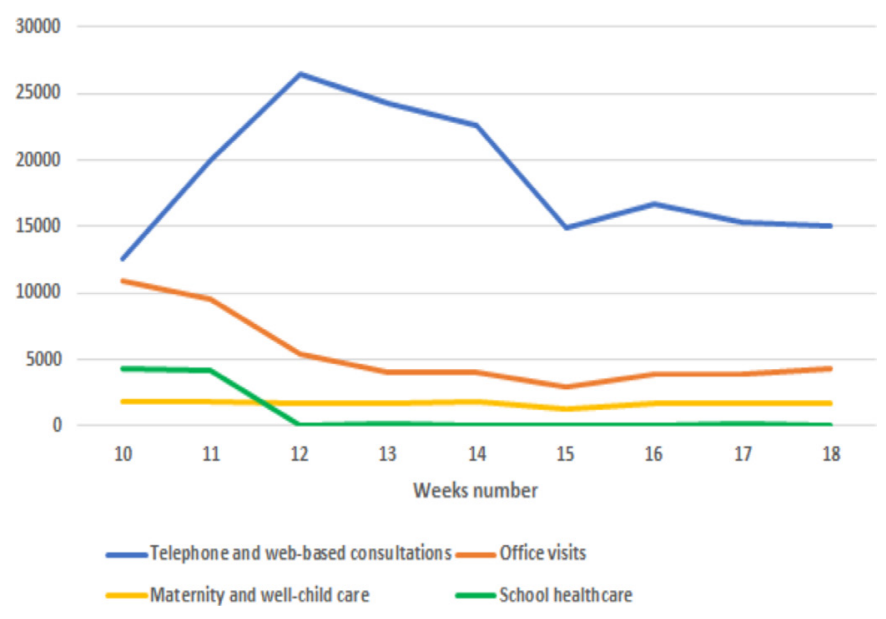

Figure 1 The number of different daytime consultation modes for each week in March and April 2020.

2019 (table 1). Telephone consultations increased by $69 \%$ $(\mathrm{p}<0.001)$, web-based consultations by $213 \% \quad(\mathrm{p}<0.001)$ and office visits decreased by $41 \%(\mathrm{p}<0.001)$ (table 1$)$. Total number of consultations in maternity and well-child care (telephone, office and home visits) decreased from $67.5 / 1000$ inhabitants $2018 / 2019$ to $65 / 1000$ inhabitants 2020 or only by $4 \%(\mathrm{p}=0.001)$. School healthcare service was stopped but maternity and well-child care services remained stable (figure 1 ).

\section{Out-of-hours consultations}

Telephone consultations increased from 125/1000 inhabitants in 2018/2019 to $320 / 1000$ inhabitants in 2020, an increase by $156 \%(\mathrm{p}<0.001)$. Home visits increased also from $4 / 1000$ inhabitants to $7 / 1000$ inhabitants, a $75 \%$ increase. However, the number of office visits decreased from 69/1000 inhabitants to $37 / 1000$ inhabitants, a $46 \%$ decrease $(\mathrm{p}<0.001)($ table 1$)$.

\section{Web chat}

In 2018 a web-chat room was established in PHC where people could seek advice and guidance. In March/April 2018 and 2019 there were 2 contacts/1000 inhabitants

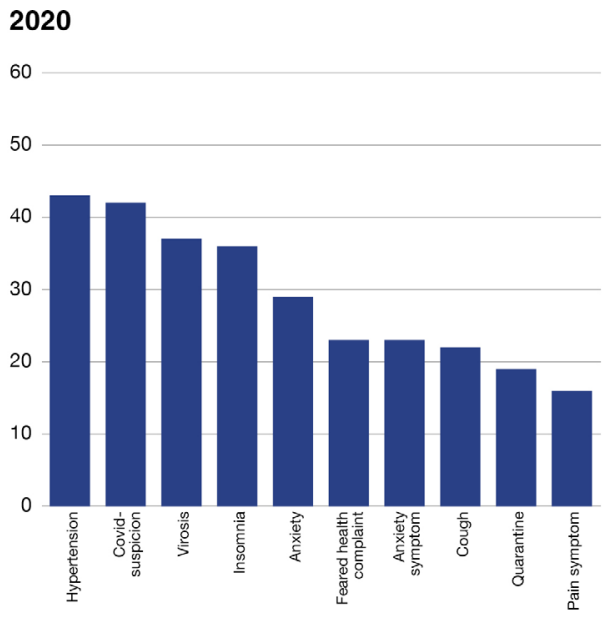

but in the same period in 2020 they were 93/1000 inhabitants $(\mathrm{p}<0.0001)$.

\section{Tests for COVID-19}

During the 2-month period, a total of 10162 samples was collected at the PHCCs and examined in the Department of Clinical Microbiology, Landspitali-The National University Hospital of Iceland. That is 43 samples per 1000 inhabitants. Of those tests $1089(11 \%)$ turned out positive.

\section{Laboratory tests}

The number of laboratory tests in prenatal care increased by $10 \%$ ( $p<0.001$ ) between the years 2018/2019 and 2020 . The number of laboratory tests in general was 335/1000 inhabitants in the years 2018/2019 but in 2020 it was $244 / 1000$ inhabitants, a $27 \%$ decrease $(p<0.001)$. The most common blood tests in both periods were blood count, thyroid stimulating hormone, vitamin $\mathrm{B}_{12}$. The most common test in 2020 was test for COVID-19 from throat and nasopharynx swabs.

\section{Most common diagnoses}

During the pandemic, the 10 most common diagnoses were substantially different from the most common diagnoses in the same months the 2 years before. Common diagnoses like immunisation, depression, hypothyroidism and lumbago are not among the most common diagnoses in the pandemic period (figure 2).

\section{Changes in the mode of patient contact leading to prescriptions and their number}

All prescriptions

In March/April 2018-2019, there was an average of 494 prescriptions issued by GPs per 1000 inhabitants and a total of 545 prescriptions per 1000 inhabitants in March/ April $2020(p<0.001)$, an increase of $10.3 \%$. The number of prescriptions from telephone and web-based consultations rose by $55.6 \%$ from 293 per 1000 inhabitants in $2018 / 2019$ to 456 in $2020(\mathrm{p}<0.001)$. At the same time, prescriptions issued by GPs during office visits,

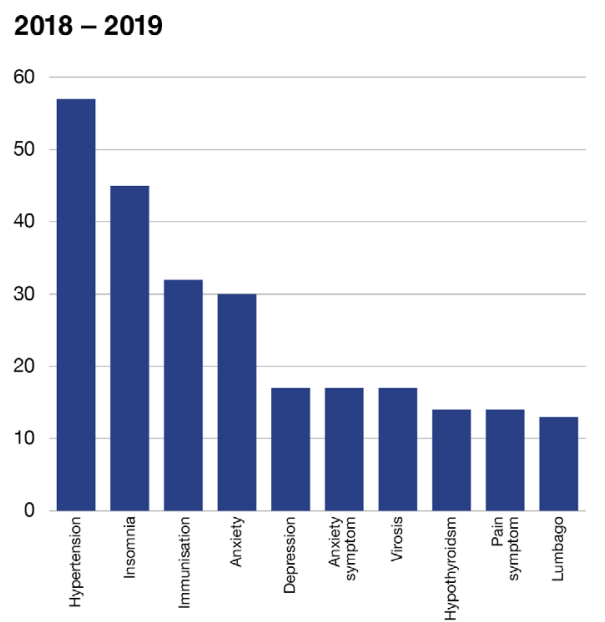

Figure 2 The 10 most common diagnoses (ICD-10) made in 2020 (left) and 2018/2019 (right). Numbers are per 1000 inhabitants. 
600

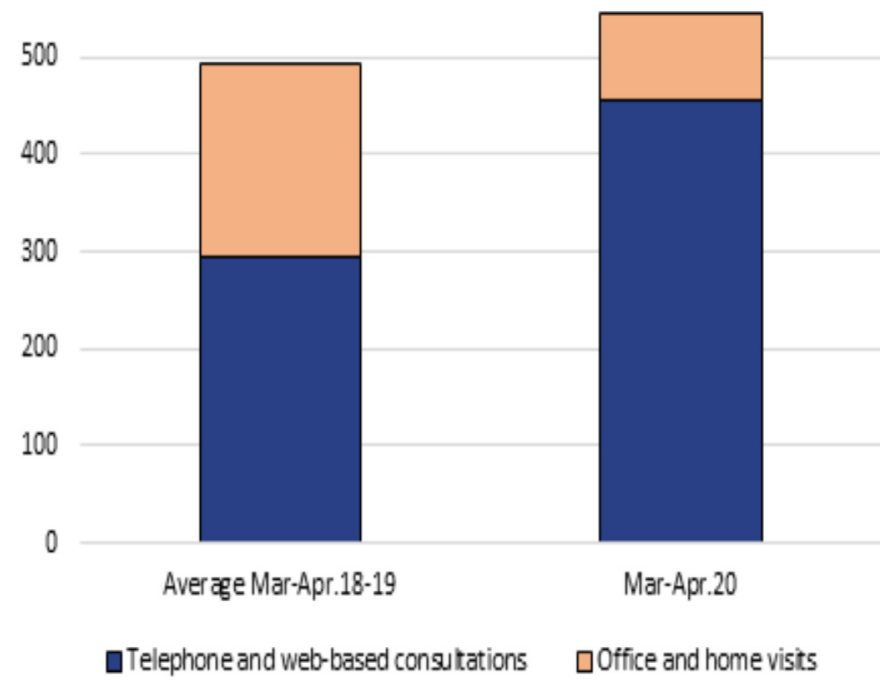

Figure 3 The number of prescriptions/1000 inhabitants in primary healthcare. Changes in the mode of patient contact during COVID-19.

plummeted as the standard care during COVID-19 by $56.2 \%$ from $201 / 1000$ to $88 / 1000$ inhabitants in 2020 $(\mathrm{p}<0.001)$ (figure 3).

\section{Antibiotic prescriptions}

The average number of antibiotic prescriptions was 45 per 1000 inhabitants in March/April 2018-2019, and a total of 44 per 1000 inhabitants in March/April 2020 $(\mathrm{p}=0.1)$. However, results also display an increase in telephone and web-based consultation prescriptions in 2020 (136.4\%) compared with more traditional direct office visit contacts, from $11 / 1000$ inhabitants to $26 / 1000$ inhabitants in $2020(\mathrm{p}<0.001)$. Meanwhile, prescriptions issued after office visits were reduced from the average in 2018 and 2019 to 2020 by almost half (47.1\%) from $34 / 1000$ inhabitants to $18 / 1000$ inhabitants $(p<0.001)$ (figure 4).

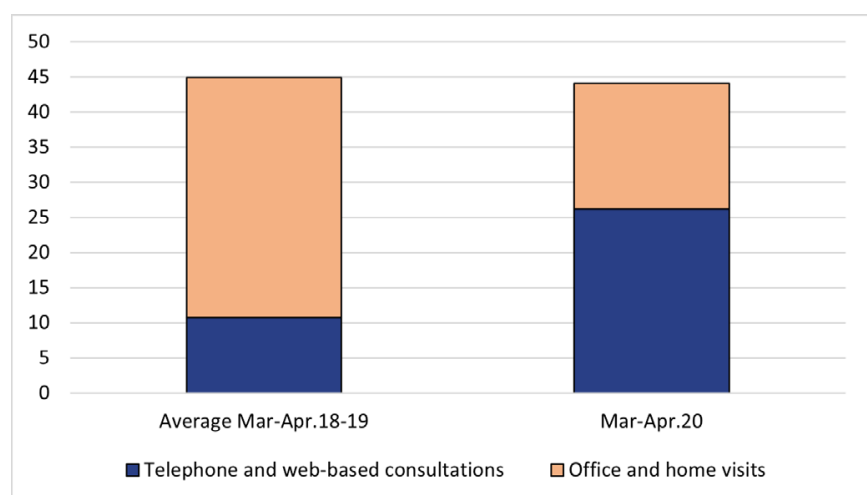

Figure 4 The number of antibiotic prescriptions/1000 inhabitants in primary healthcare. Changes in the mode of patient contact during COVID-19.

\section{DISCUSSION}

Our study illustrates the importance of well-established PHC as the place of first contact during the COVID-19 pandemic 2020. By prompt detection and effective triage of potentially infected patients the PHC managed to establish levels of care. Furthermore, our study shows the capacity and flexibility of the comprehensive service of primary care in the capital area of Reykjavík, Iceland. The size of the PHCCs, the number of professionals as well as teamwork allowed dividing up areas and services according to risk estimates, keeping the maternity care and well-child care almost at the same level as before. However, the increase in the frequency of feared health complaints (ICD-10 Z71.1) and lack of face-to-face contacts during this period, indicates a longer-lasting follow-up as a consequence of this pandemic.

Our data show a substantial increase in number of contacts with our patients during this pandemic, and an abrupt change in mode of appointments compared with the same period 2018 and 2019. Those changes were in harmony with recommendations from health authorities.

The role of out-of-hours consultations in PHC is always of immense importance and in this pandemic it played an even more significant role as part of the front-line healthcare responses.

Interestingly, there was an enormous rise in web-based consultations during the pandemic indicating that our traditional ways of assisting our patients, by either face-toface or telephone conversations, have to be revised. ${ }^{13-15}$

Of special interest is the fact that in spite of the increase in web-based and telephone consultations instead of face-to face contacts, the number of antibiotic prescriptions remained constant compared with the years before. This indicates that COVID-19-like symptoms and fear of superinfections had little impact on antibiotic prescriptions. $^{16}$

Regarding the changes in the 10 most common diagnoses it is of particular interest to observe the high number of individuals diagnosed with feared health complications in 2020. This undoubtedly indicated an area of worries in the community.

Our results show, as was expected that the list of the 10 most common diagnoses in the pandemic included diagnoses related to COVID-19, but still common diagnoses as hypertension, anxiety, insomnia and pain are among the 10 most common diagnoses. However, diagnoses such as depression, hypothyroidism and lumbago were not among 10 most common diagnoses during the epidemic. The decrease in the use of laboratory tests might indicate a change in ordinary patient care. Nevertheless, the number of drug prescriptions did not decrease and in fact increased slightly, suggesting that the prescription of continuous medication was not disrupted. Studies or reports on how general practice faced COVID-19 are scarce so comparison of our study with others is very limited. $^{10}$

One of the main concerns of the health authorities in Iceland as well as elsewhere, was whether the 
hospitals, especially the intensive care units, would be overwhelmed. The number of respirators was the critical obstacle. Therefore, the plan was, among other things, to delay the spread of the virus, thereby sharpening the gatekeeping role of the PHC and spreading the workload.

Numerous studies have been published on secondary care and hospitals' approach to the care of patients with COVID-19 during the pandemic, but studies in primary care are still scarce. At present most of the literature published on the effect on primary care are reports from opinion leaders, describing the actions to be taken and confirming the importance of primary care as the first contact of care. ${ }^{1-3} 17-20$

Furthermore, the importance of telemedicine (audio and or video consultations) has been acknowledged. ${ }^{21}$ Our results are in agreement with a recent comprehensive quantitative study from USA showing changes in the structure of the primary care delivery, especially with regard to telemedicine encounters. ${ }^{22}$ Although not directly comparable to our results a recent study from Belgium, based on qualitative interviews with GPs, illustrates that the sudden shift in healthcare delivery has a profound impact on the core competencies of primary care. ${ }^{23}$ A quantitative analysis of primary care medical records in a deprived area in the UK showed that the indirect effect of the COVID-19 pandemic in that area was a decrease in common diagnoses such as diabetes, indicating a large number of patients having underdiagnosed conditions. ${ }^{24}$ Our study also showed changes in the diagnosis pattern and indicated that the flexibility in our PHC could preserve preventive measures and probably the most common diagnoses. Moreover, our study supports the experience from the coronavirus outbreak in China regarding the importance of $\mathrm{PHC}$, especially that we will be 'first in and last out'. ${ }^{\text {' }}$

After the first wave of the COVID-19 epidemic in Iceland, national data on 8 June show that 1807 persons became infected with the SARS-CoV-2 virus $(4.9 / 1000)$ of whom 118 patients were hospitalised (or $6.5 \%$ of those infected) and of whom 30 needed intensive care. Ten people died $(0.5 \%$ of those infected $){ }^{25}$ These figures are the lowest in the Nordic countries and also in comparison to others with similar age distribution and standard of living. ${ }^{26}$

History has told us that epidemics ultimately resolve and they usually follow a certain pattern and the first wave of COVID-19 epidemic in Iceland appeared to do just that. $^{27} 28$

If the COVID-19 pandemic continues for the next years the PHC has gained important knowledge and experience on how to manage and optimise the care of their patients during such a serious outbreak. ${ }^{29}$ However, due to the methodological design of this study we were not able to explore the possible long-term effects of changing the strategy in PHC which is definitely something future researches must investigate.

\section{Conclusions and implications}

We conclude that PHC in Iceland managed to accomplish its role as a first-line gatekeeper and was able to change its strategy swiftly in an effort to deal with COVID-19. At the same time the traditional maternity and well-child care was preserved. The use of PHC for non-COVID-related issues decreased, indicating a substantial flexibility in the organisation. Whether and how new technology, such as web-based and video consultations, will be taken into consideration as a future option for PHC is a topic for further research and quality development.

Acknowledgements The authors thank the chief medical doctor at the Primary Health Care of the Capital Area, Reykjavik, the Primary Health Care of Hofdi, Reykjavik, the Primary Health Care of Lagmuli, Reykjavik, the Primary Health Care of Urdarhvarf, Reykjavik, the Primary Health Care of Salastodin, Reykjavik, and The Out-of-Hours Clinic in Reykjavik, Iceland.

Contributors All authors contributed to the planning, conduct and reporting of the study. ELS, JSJ, MOT, HH, KL worked on acquisition of the data. ELS, ABB and JSJ drafted the manuscript with input from MOT, HH, KL and JAS which was critically reviewed by all the authors. HH performed the statistical analysis. ELS, ABB, JSJ, MOT, HH, KL, JAS read and approved the final version of the manuscript.

Funding This research was supported by the Research Fund of the Icelandic College of Family Physicians.

Competing interests None declared.

Patient and public involvement Patients and/or the public were not involved in the design, or conduct, or reporting, or dissemination plans of this research.

Patient consent for publication Not required.

Ethics approval The study was approved by The National Bioethics Committee and the Data Protection Authority in Iceland (VSN-20-095).

Provenance and peer review Not commissioned; externally peer reviewed.

Data availability statement Data are available upon reasonable request. The data were retrieved from a medical records database in the Primary Health Care of the Capital Area (PHCCA). The encrypted data are kept at the PHCCA and can be made available on reasonable request if permitted by the abovementioned health authorities.

Open access This is an open access article distributed in accordance with the Creative Commons Attribution Non Commercial (CC BY-NC 4.0) license, which permits others to distribute, remix, adapt, build upon this work non-commercially, and license their derivative works on different terms, provided the original work is properly cited, appropriate credit is given, any changes made indicated, and the use is non-commercial. See: http://creativecommons.org/licenses/by-nc/4.0/.

\section{ORCID iDs}

Emil Larus Sigurdsson http://orcid.org/0000-0003-0796-565X

Kristjan Linnet http://orcid.org/0000-0002-0189-9519

\section{REFERENCES}

1 Rasanathan JJK, Nolan T. A "Deep Breath In" for GPs. BMJ 2020;369:m1437.

2 Kamerow D. Covid-19: Don't forget the impact on US family physicians. BMJ 2020;368:m1260.

3 Fraher EP, Pittman P, Frogner BK, et al. Ensuring and sustaining a pandemic workforce. N Engl J Med 2020;382:2181-3.

4 The Lancet. The Astana declaration: the future of primary health care? Lancet 2018;392:1369.

5 Razai MS, Doerholt K, Ladhani S, et al. Coronavirus disease 2019 (covid-19): a guide for UK GPs. BMJ 2020;368:m800.

6 Greenhalgh T, Koh GCH, Car J. Covid-19: a remote assessment in primary care. BMJ 2 020:m1182.

7 Landsáætlun CBRNE. Published by Iceland's chief epidemiologist and the Icelandic Police's department of civil protection and emergency management, 2020.

8 Heimsfaraldur - Landsáætlun edition 3.1. published by Iceland's chief epidemiologist and the Icelandic Police's department of civil 
protection and emergency management, may 25th 2020. Available: https://www.landlaeknir.is/utgefid-efni/skjal/item29596/

9 Gudbjartsson DF, Helgason A, Jonsson $\mathrm{H}$, et al. Spread of SARS-CoV-2 in the Icelandic population. $N$ Engl J Med 2020;382:2302-15.

10 Mash B. Primary care management of the coronavirus (COVID-19). S Afr Fam Pract 2020;62:e1-4.

11 Sigurgeirsdóttir S, Waagfjörð J, Maresso A. Iceland: health system review. Health Syst Transit 2014;16:1-182.

12 Iceland S. Available: https://px.hagstofa.is/pxis/pxweb/is/?rxid= 633839273-14c5-42ba-9a72-1d87b83270c4

13 Keesara S, Jonas A, Schulman K. Covid-19 and health care's digital revolution. N Engl J Med 2020;382:e82.

14 Duffy S, Lee TH. In-Person health care as option B. N Engl J Med 2018;378:104-6.

15 Ackerman SL, Dowdell K, Clebak KT, et al. Patients assess an eConsult model's acceptability at 5 US academic medical centers. Ann Fam Med 2020;18:35-41.

16 Hsu J. How covid-19 is accelerating the threat of antimicrobial resistance. BMJ 2020;369:m1983.

17 Li DKT. Challenges and responsibilities of family doctors in the new global coronavirus outbreak. Fam Med Community Health 2020;8:e000333.

18 Kidd MR. Five principles for pandemic preparedness: lessons from the Australian COVID-19 primary care response. Br J Gen Pract 2020;70:316-7.

19 Desborough J, Hall Dykgraaf S, de Toca L, et al. Australia's national COVID-19 primary care response. Med J Aust 2020;213:104-6.
20 Huston P, Campbell J, Russell G, et al. COVID-19 and primary care in six countries. BJGP Open 2020;4. doi:10.3399/bjgpopen20X101128. [Epub ahead of print: 27 Oct 2020].

21 Greenhalgh T, Wherton J, Shaw S, et al. Video consultations for covid-19. BMJ 2020;368:m998.

22 Alexander GC, Tajanlangit M, Heyward J, et al. Use and content of primary care office-based vs telemedicine care visits during the COVID-19 pandemic in the US. JAMA Netw Open 2020;3:e2021476.

23 Verhoeven V, Tsakitzidis G, Philips H, et al. Impact of the COVID-19 pandemic on the core functions of primary care: will the cure be worse than the disease? A qualitative interview study in Flemish GPs. BMJ Open 2020;10:e039674.

24 Williams R, Jenkins DA, Ashcroft DM, et al. Diagnosis of physical and mental health conditions in primary care during the COVID-19 pandemic: a retrospective cohort study. Lancet Public Health 2020;5:e543-50.

25 The Directorate of health and the Department of civil protection and emergency management. Available: https://www.covid.is/english

26 Johns Hopkins University. COVID-19 Dashboard by the center for systems science and engineering (CSSE), 2020. Available: https:// gisanddata.maps.arcgis.com/apps/opsdashboard/ index.html\#/bda7 594740fd40299423467b48e9ecf6

27 Rosenberg CE. What is an epidemic? AIDS in historical perspective. Daedalus 1989:1-17.

28 Jones DS. History in a Crisis - Lessons for Covid-19. N Engl J Med 2020;382:1681-3.

29 Rauh AL, Linder JA. Covid-19 care before, during, and beyond the hospital. BMJ 2020;369:m2035. 